\title{
An aroA mutant of Yersinia pestis is attenuated in guinea-pigs, but virulent in mice
}

\author{
Petra C. F. Oyston, Paul Russell, E. Diane Williamson and \\ Richard W. Titball
}

Chemical and Biological Defence Establishment, Porton Down, Salisbury, Wiltshire SP4 0JQ, UK

\author{
Author for correspondence: Petra C. F. Oyston. Tel: +44 1980 613320. Fax: +44 1980613284. \\ e-mail:100432.3200@compuserve.com
}

\begin{abstract}
This study describes a PCR-based approach for the production of a rationally attenuated mutant of Yersinia pestis. Degenerate primers were used to amplify a fragment encoding $\mathbf{9 1 . 4 5 \%}$ of the aroA gene of $Y$. pestis MP6 which was cloned into pUC18. The remainder of the gene was isolated by inverse PCR. The gene was sequenced and a restriction map was generated. The $Y$. pestis aroA gene had $75 \cdot 9 \%$ identity with the aroA gene of Yersinia enterocolitica. The cloned gene was inactivated in vitro and reintroduced into $Y$. pestis strain GB using the suicide vector pGP704. A stable aro-defective mutant, $Y$. pestis GBDaroA, was isolated and its virulence was examined in vivo. The mutant was attenuated in guinea-pigs and capable of inducing a protective immune response against challenge with the virulent $Y$. pestis strain GB. Unusually for an aro-defective mutant, the $Y$. pestis aroA mutant was virulent in mice, with a median dose which induced morbidity or death similar to that of the wildtype, although time to death was significantly prolonged.
\end{abstract}

Keywords: Yersinia pestis, aro $A$

\section{INTRODUCTION}

Yersinia pestis is the causative organism of bubonic and pneumonic plague and results in a high rate of mortality. It is capable of infecting man and a wide range of animals, with transmission occurring primarily by flea bites. Virulence of the bacterium is due to the expression in vivo of a complex array of factors (Straley \& Perry, 1995). The prevention of plague is based upon vaccination, but existing whole-cell plague vaccines produce a range of side-effects, making them unsuitable for widespread use (Marshall et al., 1974; Meyer et al., 1974a; Reisman, 1907). Candidate subunit vaccines based on the $Y$. pestis $\mathrm{F} 1$ and $\mathrm{V}$ antigens have been shown to induce protection against plague (Oyston et al., 1995; Leary et al., 1995). However, F1-defective mutants of $Y$. pestis have recently been identified which are still virulent (Davis et al., 1996; Drozdov et al., 1995). A rationally attenuated $Y$. pestis strain would enable the presentation of a wider variety of antigens, including $F 1$ and V, to the immune system, thus enhancing protective efficacy. The existing whole-cell vaccines currently licensed for human use may leave vulnerable mucosal surfaces unprotected as they are

\footnotetext{
Abbreviations: DHB, dihydroxybenzoic acid; PABA, para-aminobenzoic acid.

The EMBL/GenBank/DDBJ accession number for the sequence reported in this paper is $L 46372$.
}

administered parenterally and may not effectively induce a mucosal immune response (McGhee et al., 1992). The pneumonic form of plague is highly infectious, due to the large numbers of plague bacilli released in aerosols (Cowling \& Moss, 1994). A live attenuated mutant strain would be amenable to oral dosing and thus should effectively induce mucosal immunity to protect against pneumonic plague.

Bacteria possess a linear biochemical pathway for the synthesis of aromatic amino acids. The aro $A$ gene encodes 5 -enolpyruvylshikimate-3-phosphate synthase, which is involved in the conversion of shikimic acid into chorismic acid, a common intermediate in the synthesis of several compounds, including aromatic amino acids, para-aminobenzoic acid (PABA), 2,3-dihydroxybenzoic acid (DHB) and para-hydroxybenzoic acid. Interruption of this pathway produces a requirement for PABA and DHB, which are not available in mammalian tissues. Therefore the bacteria are only capable of limited replication before being cleared from the host.

Attenuated strains of a range of bacterial species have been produced by inactivation of genes in the aromatic acid biosynthetic pathway. Aromatic-dependent ( $\Delta$ aro $)$ mutants of Salmonella, Pasteurella multocida, Aeromonas salmonicida, Yersinia enterocolitica, Bordetella pertussis, Bacillus antbracis and Listeria monocytogenes (Hoiseth \& Stocker, 1981; Levine et al., 1987; Homchampa et al., 1992; 
Vaughan et al., 1993; Bowe et al., 1989; Roberts et al., 1990; Ivins et al., 1990; Alexander et al., 1993) have all been shown to be avirulent and to stimulate protective immunity. Salmonella typhimurium $\triangle$ aro $A$ administered orally to mice was capable of invasion from the gut, followed by colonization of the Peyer's patches, liver and spleen (Maskell et al., 1987). Multiplication was selflimiting and the salmonellae were cleared after a period of several weeks. However, $Y$. enterocolitica $\triangle a r o A$ could establish only a short-lived colonization of the reticuloendothelial system and required repeated inoculations to induce immunity (Bowe et al., 1989).

$Y$. pestis auxotrophic mutants with a requirement for exogenous supplies of amino acids, including phenylalanine, have been isolated previously and observed to be virulent in mice (Burrows, 1960, 1963). However, the exact mutation to produce phenylalanine dependence was not characterized and it is not possible to know whether genes other than those involved in the production of this aromatic amino acid were expressed normally. In this study, we have constructed a defined isogenic $\Delta$ aro mutant and tested its stability, immunogenicity and protective efficacy in vivo.

\section{METHODS}

Bacteria, plasmids, media and growth conditions. $Y$. pestis laboratory strain MP6 and the human isolate strain GB were routinely cultured aerobically at $28^{\circ} \mathrm{C}$ in Blood Agar Base $(\mathrm{BAB})$ broth or on $\mathrm{BAB}$ agar. Yersinia selective agar base (YSA) was obtained from Oxoid.

S. typhimurium SL3261 (Hoiseth \& Stocker, 1981) was provided by B. A. D. Stocker, Stanford University, CA, USA.

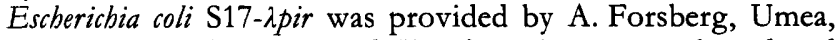
Sweden. S. typhimurium and E. coli strains were cultured and stored as described by Sambrook et al. (1989).

Defined media were prepared as described by Straley \& Bowmer (1986), omitting, when necessary, the aromatic amino acids tyrosine, tryptophan and phenylalanine, which were normally present at a final concentration of $1 \mathrm{mM}, 0 \cdot 1 \mathrm{mM}$ and $1 \mathrm{mM}$, respectively. For all media, ampicillin was added as required at a final concentration of $25 \mu \mathrm{g} \mathrm{ml}$.

Plasmid pUC18 was obtained pre-digested with $S m a I$ and pretreated with calf intestinal alkaline phosphorylase (Boehringer Mannheim). The vectors pGP704 (Miller \& Mekalanos, 1988) and pNJ5000 (Grinter, 1983) were kindly provided by M. Tully, CAMR, Salisbury, UK, and B. Wren, St Bartholomew's Hospital, London, UK, respectively.

Preparation and manipulation of DNA. DNA was isolated from Y. pestis by the method of Marmur (1961). Large- and small-scale plasmid isolations, restriction enzyme digests, bluntending of DNA fragments and ligations were performed as described by Sambrook et al. (1989). Restriction endonucleases, T4 DNA ligase, DNA polymerase I, large fragment (Klenow enzyme), sequencing-grade Taq polymerase and polynucleotide kinase were obtained from Boehringer Mannheim.

Electroporation. E. coli strains were transformed following electroporation as described by Dower et al. (1988), using a Gene Pulser apparatus (Bio-Rad) set at $2 \cdot 5 \mathrm{kV}, 25 \mu \mathrm{F}$ and $800 \Omega$. Following electroporation, bacteria were incubated at $37^{\circ} \mathrm{C}$ for $1 \mathrm{~h}$ without selection and then plated onto the appropriate selective media.
Bacterial conjugation. Plasmids were introduced into $Y$. pestis by conjugation in a three-way mating (Grinter, 1983), using a $Y$.

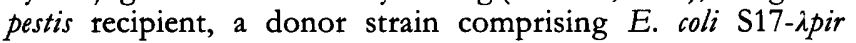

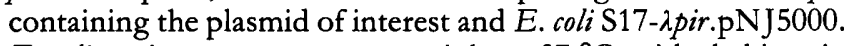
E. coli strains were grown overnight at $37^{\circ} \mathrm{C}$, with shaking, in $\mathrm{LB}$ containing the appropriate antibiotic. Y. pestis strain GB was grown at $28^{\circ} \mathrm{C}$ overnight with shaking in $\mathrm{BAB}$. A $1 \mathrm{ml}$ aliquot of each strain was washed in LB and resuspended to $100 \mu \mathrm{l}$ in LB. Equal volumes $(50 \mu \mathrm{l})$ of the three strains were mixed and $100 \mu \mathrm{l}$ was spotted onto an L-agar plate. After incubation at $28^{\circ} \mathrm{C}$ for $4 \mathrm{~h}$, the bacteria were removed from the plate using a sterile swab and resuspended in $1 \mathrm{ml} \mathrm{LB}$. The cells were washed twice in LB, diluted and plated onto YSA containing $25 \mu \mathrm{g}$ ampicillin $\mathrm{ml}^{-1}$ and incubated at $28^{\circ} \mathrm{C}$. E. coli was unable to grow on the YSA plates as quickly as $Y$. pestis, and grew very palely pink, while the $Y$. pestis colonies were a very dark pink.

Cloning and sequencing of the aroA gene of $Y$. pestis. Degenerate oligonucleotide primers were designed by comparison of the nucleotide sequences of E. coli, S. typhimurium, $B$. pertussis and $Y$. enterocolitica. These primers corresponded to nucleotides 4-20 (GAATCCCTGACKTTACA, where $\mathrm{K}=\mathrm{G}$ or $\mathrm{T}$ ) of the $E$. coli aro $A$ gene, with the complementary primer (CACATCGCCATVCGGTG, where V=G, C or A) corresponding to nucleotides 1105-1121 (Fig. 1). Using these oligonucleotide primers in PCR (Dybvig et al., 1992), a DNA fragment was obtained after 35 cycles of amplification $\left(95^{\circ} \mathrm{C}\right.$, $15 \mathrm{~s} ; 50^{\circ} \mathrm{C}, 15 \mathrm{~s} ; 72^{\circ} \mathrm{C}, 30 \mathrm{~s}$; Perkin Elmer 9600 GeneAmp PCR System). The fragment was purified, blunt-ended and ligated into pUC18 to produce PYPA7. Synthetic oligonucleotide primers were used to sequence the fragment by the dideoxy chain-termination method, using a PRISM Ready Reaction Dye Terminator Cycle Sequencing kit (Applied Biosystems). Samples were loaded on an ABI 373A automated DNA sequencer and electrophoresed through a $6 \%(\mathrm{w} / \mathrm{v})$ gel, and chromatograms were analysed using SeqEd (ABI). The remaining bases of the aro $A$ gene sequence were obtained by inverse PCR (Havard et al., 1992) following digestion of wholecell $Y$. pestis DNA with SacII or CfoI.

Determination of virulence for mice and guinea-pigs. $\mathrm{BALB} / \mathrm{c}$ female mice (6 week old) and female (young, Duncan Hartley) guinea-pigs were used throughout. The median doses of the wild-type and mutant strains which induced morbidity or death in mice were assessed by subcutaneous injection of groups of five animals with serial dilutions of exponential-phase broth cultures grown at $28{ }^{\circ} \mathrm{C}$. Humane end-points were strictly observed, and animals deemed incapable of survival were humanely sacrificed by cervical dislocation. The median lethal dose which induced morbidity or death was determined by the method of Reed \& Muench (1938).

The virulence of the strains in guinea-pigs was assessed with cultures grown at $37^{\circ} \mathrm{C}$. Guinea-pigs challenged with $19 \cdot 1$ c.f.u. $Y$. pestis strain GB surviving to $21 \mathrm{~d}$ were killed by cervical dislocation and autopsied. One animal which had been challenged with $26 \cdot 2$ c.f.u. GB $\triangle a r o A$ was also sacrificed, bled by cardiac puncture, post-mortemed and organ smears were made. Sera were titrated by ELISA (Oyston et al., 1995) for the presence of antibodies to $\mathrm{F} 1$ and V antigens. Guinea-pigs inoculated with the aro-defective mutant were challenged with $Y$. pestis GB on day 24. Fourteen days after this second inoculation, the guinea-pigs were sacrificed and examined for the presence of internal abscesses.

Survival of $Y$. pestis GBdaroA in vivo. Two groups of 35 mice were inoculated subcutaneously with either $7.28 \times 10^{3}$ c.f.u. $Y$. pestis GB or $7 \cdot 77 \times 10^{3}$ c.f.u. GB $\Delta$ aro $A$. At $6,12,24,48,72$ and $96 \mathrm{~h}$, five mice from each group were sacrificed by cervical dislocation and spleens were removed and homogenized in 
$10 \mathrm{ml}$ PBS (Dulbecco's A recipe; Oxoid) using a stomacher (Seward Medical) on maximum setting for $2 \mathrm{~min}$ and diluted in PBS. Spleen homogenates were plated in duplicate on Congo red and YSA plates to determine the numbers of plague bacilli present.

Growth of $Y$. pestis GB $\triangle$ aroA in defined media. S. typhimurium SL3261 and $Y$. pestis GB $\Delta$ aro $A$ were grown overnight in defined medium. Aliquots $(1 \mathrm{ml})$ of each were used to inoculate $20 \mathrm{ml}$ defined medium. The cultures were grown at $28^{\circ} \mathrm{C}(Y$. pestis) or $37^{\circ} \mathrm{C}$ (S. typhimurium) with shaking and the $\mathrm{OD}_{600}$ was monitored at hourly intervals using a Philips PU8800 spectrophotometer. At stationary phase, a $1 \mathrm{ml}$ aliquot was used to inoculate a fresh $20 \mathrm{ml}$ culture, and the process was repeated. When SL3261 was not growing in fresh defined media, $100 \mu \mathrm{l}$ $1 \mathrm{mg}$ folate $\mathrm{ml}^{-1}$ was added to the broth. After a further $3 \mathrm{~h}$, $100 \mu \mathrm{l} 1 \mathrm{mg} \mathrm{PABA} \mathrm{ml}^{-1}$ and $1 \mathrm{mg} \mathrm{DHB} \mathrm{m}^{-1}$ were added and the $\mathrm{OD}_{600}$ was monitored.

\section{RESULTS}

\section{Sequence analysis of the $Y$. pestis aroA gene}

The sequence (Fig. 1) contained an open reading frame of 1275 nucleotides which encoded a protein of 425 amino acids. The nucleotide sequence exhibited $75.9 \%$ identity to the aro $A$ gene of $Y$. enterocolitica (O'Gaora et al., 1989). A high degree of identity was also identified between the predicted amino acid sequence of the aro $A$ gene from $Y$. pestis and the aro $A$ genes from E. coli, S. typhimurium, $B$. pertussis and $Y$. enterocolitica, which showed $79.5 \%$, $79 \cdot 1 \%, 52 \cdot 2 \%$ and $90 \cdot 1 \%$ identity, respectively (Fig. 2 ). When examining the sequence published here, it should be borne in mind that it was derived from a PCR product rather than a directly cloned gene and may therefore contain PCR-introduced errors. To minimize such errors, the pooled PCR products of the aro $A$ gene amplified from chromosomal DNA preparations were sequenced three times in each direction to confirm the sequence obtained from the cloned PCR-derived gene.

\section{Construction of the $Y$. pestis $\triangle$ aroA mutant}

A restriction map was generated from the sequence of the $Y$. pestis aro $A$ gene. A unique $\mathrm{SacII}$ site and two $\mathrm{ClaI}$ sites were identified, allowing the deletion of an internal $293 \mathrm{bp}$ fragment. Plasmid pYPA7 was digested with ClaI and SacII, blunt-ended and re-ligated. Loss of the $293 \mathrm{bp}$ fragment was confirmed by PCR, restriction digests and sequencing. The deleted aro $A$ gene fragment was excised from pUC18 by digestion with $S a c \mathrm{I}$ and $\mathrm{SalI}$ and cloned into SacI/Sall-cut pGP704 to produce pGPYP $\Delta \mathrm{A} 7$. The plasmid was electroporated into E. coli S17- $\lambda$ pir, mobilized into $Y$. pestis $\mathrm{GB}$ and transconjugants were selected on YSA plates containing $25 \mu \mathrm{g}$ ampicillin $\mathrm{ml}^{-1}$. Colonies which appeared on the selective plates resulted from integration of pGPYP $\triangle A 7$ into the chromosome by a single cross-over event. Five colonies were picked and replated twice on nonselective media before ampicillinsensitive revertants appeared due to a second cross-over event. As either the wild-type copy of the gene originally present on the $Y$. pestis chromosome or the plasmid-borne mutated gene could have been excised, the deletion was confirmed by PCR (Fig. 3). The mutant, strain GB $\triangle$ aro $A$, was unable to grow on defined media without supple- ments of aromatic amino acids, whereas the wild-type grew on both types of media.

\section{Growth of $Y$. pestis GBAaroA in defined media}

The growth of $S$. typhimurium SL3261 (aro $A$ bis) in defined media containing aromatic amino acids and histidine was measured. By the third subculture in defined media, the culture showed no increase in optical density after incubation for up to $24 \mathrm{~h}$ at $37^{\circ} \mathrm{C}$. Supplementing the media with PABA and DHB, but not folate alone, resulted in rapid growth of the organism. $Y$. pestis $\mathrm{GB} \Delta a$ aro $A$ was also able to grow in the same batch of media; however, repeated subculture did not result in limitation of growth, even by the seventh subculture into fresh media. Therefore, unlike $S$. typhimurium SL3261, the aro $A$-defective $Y$. pestis mutant was not starved of PABA and DHB in the defined media.

\section{Virulence of $Y$. pestis $\mathrm{GB} \Delta$ aroA in vivo}

$Y$. pestis $\mathrm{GB}$ was virulent in $\mathrm{BALB} / \mathrm{c}$ mice, with a median dose which induced morbidity or death of approximately 1 c.f.u., confirming the virulence of this strain observed previously (Russell et al., 1995). The median dose of $\mathrm{GB} \triangle a \operatorname{co} A$ required to produce morbidity or death was 1.66 c.f.u., but the mean time to death of $158.9 \pm 8.6 \mathrm{~h}$ was significantly longer than with strain GB $(108.3 \pm 7.75 \mathrm{~h}$; $P<0.001)$. Y. pestis was isolated from organ smears from the mice challenged with GB $\triangle$ aro $A$. PCR amplification of the aro $A$ gene of the recovered organisms showed that the mutant had not reverted to the wild-type.

$Y$. pestis infection in guinea-pigs caused a protracted disease compared to that seen in mice. Typically the animals appeared ruffled, lost weight and became less active. In some cases, there was asymmetrical paralysis of the rear limbs, followed by an apparent depression of the respiratory rate. The animals were humanely killed at this time. Autopsy revealed abscesses in the liver and spleen, and the organs were enlarged. $Y$. pestis GB produced disease in guinea-pigs. One animal died within $21 \mathrm{~d}$ and the livers and spleens of all but one of the remaining animals were shown to be covered by abscesses upon post-mortem on day 21 . The guinea-pigs challenged with GBDaro $A$ all survived to day 21 , and autopsy of one animal at this time revealed no apparent internal abscesses. Serum from the autopsied animal had a specific anti-F1 antigen titre of $1: 1600$ and an anti- $\mathrm{V}$ antigen titre of $1: 800$. Guinea-pigs from both challenge groups had a subcutaneous lesion at the site of injection.

The remaining guinea-pigs which had originally received GB $\Delta$ aro $A$ were challenged with $Y$. pestis GB $\left(9 \cdot 26 \times 10^{3}\right.$ $9 \cdot 26 \times 10^{6}$ c.f.u.). All the animals survived the challenge with no apparent ill-effects over $14 \mathrm{~d}$. Post-mortem after this interval revealed all the surviving animals to be healthy, with no internal abscesses. No $Y$. pestis was isolated from smears of livers and spleens.

\section{Survival of the aro-defective mutant in vivo}

Following subcutaneous inoculation of $Y$. pestis GB or GB $\triangle$ aro $A$ in mice, no bacteria were isolated from the 
RTGCTGGAATCCCTGACCTTACAACCCATTGCCCTAGTTAATGGCACCGTTAATTTACCTGGTTCGAAGAGTGTCTCTAACCGCGCACTGCTTCTGGCCG 100

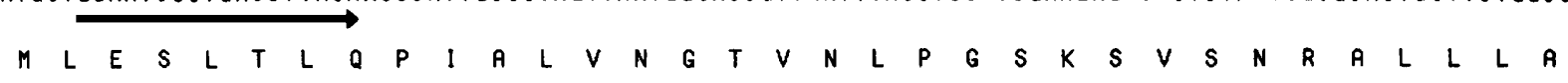

CGTTGGCCGAAGGGACCACTCAGTTGAATAACGTGTTAGACAGCGATGACATCCGCCACATGCTCAATGCATTACAGGCATTAGGGGTGGACTTCCGCCT 200

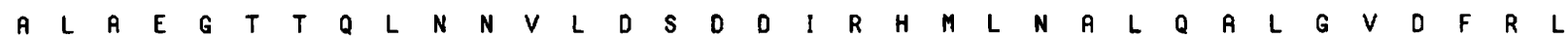

TTCTGCTGATCGCACATGCTGTGAGGTTGATGGTCTGGGGGGGAATTAGTGGCTGAACAGCCATTGTCGCTTTTCTTGGGCAATGCCGGCACAGCCATG 300

$\begin{array}{lllllllllllllllllllllllllllllllllll}S & A & D & R & T & C & C & E & V & D & G & L & G & G & K & L & V & A & E & Q & P & L & S & L & F & L & G & N & A & G & T & A & M\end{array}$

CGTCCTTTGGCCGCGGTGTTATGTTTGGGTAATAGCGATATCGTACTGACGGGTGAGCCTCGGATGAAGGAGCGGCCAATTGGCCATTTGGTGGATGCGC 40O

$\begin{array}{llllllllllllllllllllllllllllllllllll}R & P & L & A & A & V & L & C & L & G & N & S & D & I & V & L & T & G & E & P & R & M & K & E & R & P & I & G & H & L & V & D & A\end{array}$

TACGTCAGGGCGGTGCACAGATCGATTATCTGGAGCAAGAAAATTACCCGCCATTACGTTTACGTGGTGGTTTCCGAGGGGGGGAGTTAACTGTTGATGG 500

$L \begin{array}{lllllllllllllllllllllllllllllllllllllllllll} & R & Q & G & G & A & Q & I & D & Y & L & E & Q & E & N & Y & P & P & L & R & L & R & G & G & F & R & G & G & E & L & T & V & D & G\end{array}$

GCGTGTCTCTAGCCAGTTCCTGACTGCTTTATTGATGACCGCCCCGCTGGCGGAGCAAGATACGACTATTCGGATTATGGGTGATCTGGTTTCCAAACCT E0O

$\begin{array}{llllllllllllllllllllllllllllllllllllllllll}R & V & S & S & Q & F & L & T & A & L & L & M & T & A & P & L & A & E & Q & D & T & T & I & R & I & M & G & D & L & V & S & K & P\end{array}$

TATATCGATATTACTCTGCACTTGATGAAAGCATTTGGTATTGACGTGGGGCATGAGAACTACCAAATTTTCCACATCAAAGGGGCCAGACCTACCGCT 70O

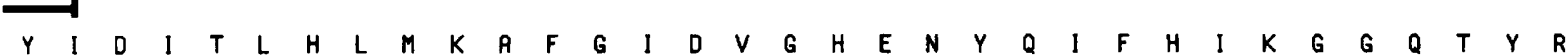

CACCAGGGACTTATTTGGTTGAGGGCGATGCCTCGTCGGCTTCCTACTTCTTAGCGGCTGCGGCTATTAAGGGGGGACAGTGCGTGTCACTGGTATTGG 800

$\begin{array}{llllllllllllllllllllllllllllllllllll}S & P & G & T & Y & L & V & E & G & D & A & S & S & A & S & Y & F & L & A & A & A & A & I & K & G & G & T & V & R & V & T & G & I & G\end{array}$

CAAGRAAAGTGTACAGGGCGACACTARATTTGCCGRTGTGTTGGAAAAAATGGGCGCGAAAGTGACGTGGGGGGATGATTATATCGAGTGCAGTCGTGGT SOO

$\begin{array}{llllllllllllllllllllllllllllllllll}K & K & S & V & Q & G & D & T & K & F & A & D & V & L & E & K & M & G & A & K & V & T & W & G & D & D & Y & I & E & C & S & R & G\end{array}$

GAATTACAGGGCATTGACATGGATATGAACCACATTCCTGATGCTGCAATGACCATTGCGACTACGGCATTATTTGCCACGGGTCCAACGACGATCCGCA 100O

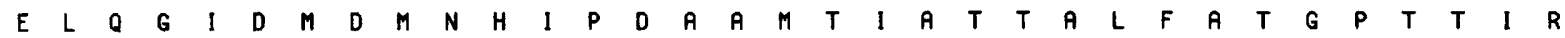

ATATCTACAACTGGCGGGTAAAAGAAACTGACCGGCTGACGGCGATGGCAACCGAGTTGAGAAAAGTAGGTGCTGAAGTGGAAGAGGGGGAAGATTACAT 1100

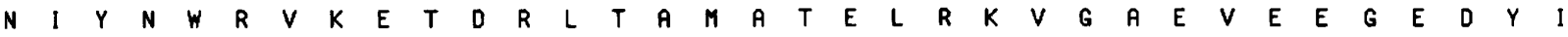

CCGCGTGGTTCCACCCTTGCAGCTAACTGCTGCAGATATTGGTACCTACGATGACCACCGTATGGCGATGTGTTTCTCGCTGGTCGCGTTATCAGATACC 1200

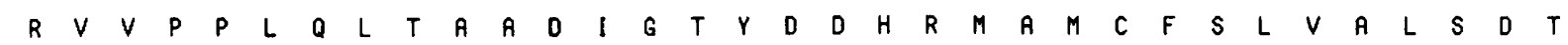

CCCGTGACGATCCTTGACCCGAATGTACCGCAAAAACCTTCCCTGATTATTTTGAACAGTTTGCGCGAAAGTGA 1275

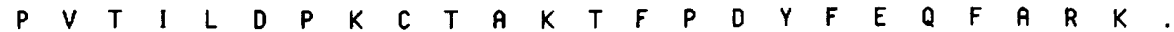

Fig. 1. Nucleotide and deduced amino acid sequences of the aroA gene of $Y$. pestis. The internal region of the gene deleted to generate the inactivated gene in PGPYP $\triangle A 7$ is underlined by a solid bar from base 312 to base 605 . Arrows under the sequence indicate the bases corresponding to the oligonucleotide primers used to amplify the fragment cloned into pUC18 to produce pYPA7.

blood during the first $24 \mathrm{~h}$. Bacteraemia then increased over several days. The spleens of both groups of mice were colonized by $24 \mathrm{~h}$, with numbers of bacteria increasing to over $10^{8}$ c.f.u. $\mathrm{g}^{-1}$ at the termination of the experiment at $96 \mathrm{~h}$. The mean times to death for two groups of five mice challenged with a high dose of approximately $7 \times 10^{7}$ c.f.u. of either strain GB or GB $\triangle$ aro $A$ were $82 \cdot 9 \pm 6.3 \mathrm{~h}$ and $117 \cdot 1 \pm 9.6 \mathrm{~h}$, respectively.

\section{DISCUSSION}

One of the earliest descriptions of an attenuating mutation in a bacterium concerned purine dependence of $Y$. pestis (Burrows, 1963). This mutant was generated by classical clonal selection techniques. Other spontaneous mutants of $Y$. pestis are currently available as vaccines for the prevention of plague, e.g. strains EV76 and Haffkine. However, the exact nature of these attenuations has not been characterized and the side-effects of vaccinating with these strains were sufficiently severe to hospitalize 2 out of 12 volunteers in one study (Meyer, 1970). Formalin-killed whole-cell vaccines are also available, but these are highly heterogeneous with variable endotoxin content and their side-effects make them unsuitable for general use (Marshall et al., 1974; Meyer et al., 1974a ; Reisman, 1907). The advantages of rationally attenuated auxotrophic strains of other bacterial species have been described previously by Clements et al. (1992) and a rationally attenuated strain of $Y$. pestis may overcome some of the problems encountered with existing vaccines, since the exact nature of the mutation is known and the degree of attenuation can thus be controlled (Sigwart et al., 1989; MacFarland \& Stocker, 1987).

The $\operatorname{aro} A$ gene has been sequenced from a range of bacterial species. This enabled degenerate PCR primers to be designed from regions of identity. This study found a high level of identity between the deduced amino acid 


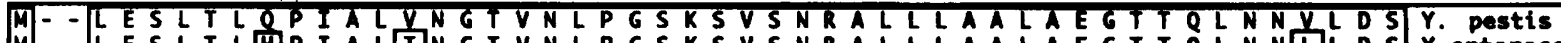

M- - LE S L T L H

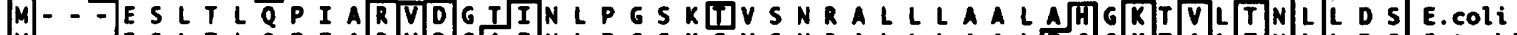

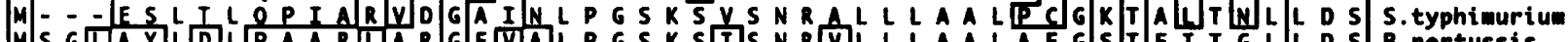

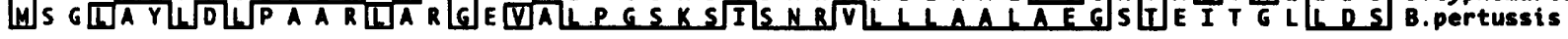

DDIRHMLNALQALGVDFRLSADRTCCEVDGLGGRLVAEQPLSLFLGNAGTY. pestis

D D IR H M L N A L OA L G V K Y R L S A D R T R C EYDG

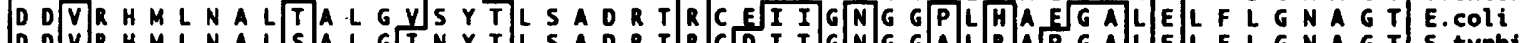

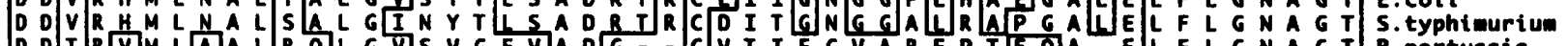

D D T $R$ R

AMRPLATYLCLGNSOIVLTGEPRMRERPIGHLVOALROGGAQIOYLEQENY. PEStis

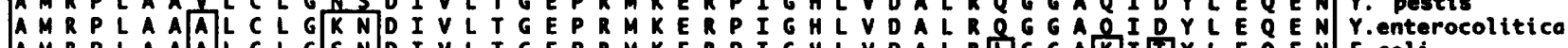

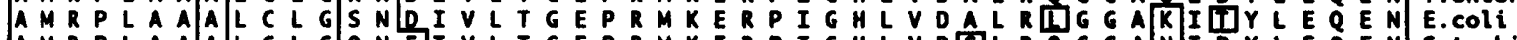

A M R P LA A A $A$ C $L G Q N$ E

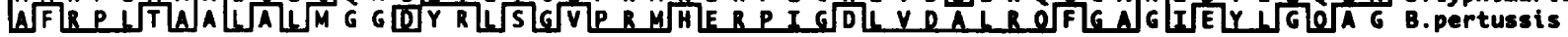

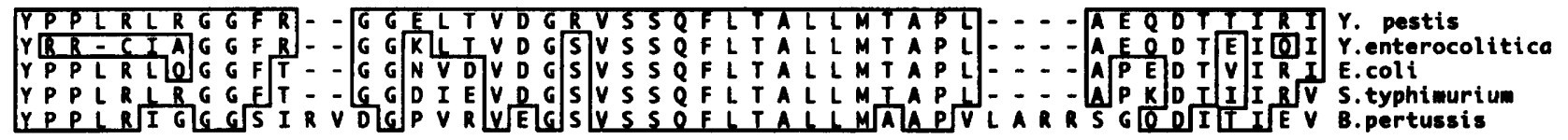

MGDLVSKPYIDITLHLMKAFGIDVGHENYQIFHIRGGQTYRSPGTYLVEG Y. pestis

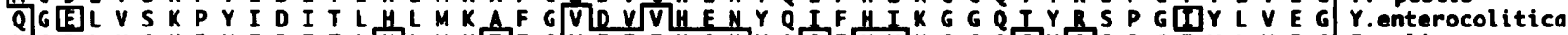

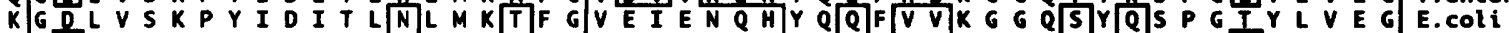

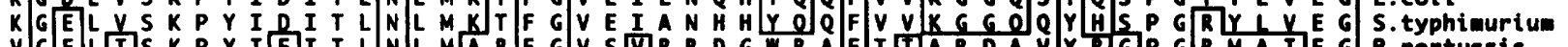

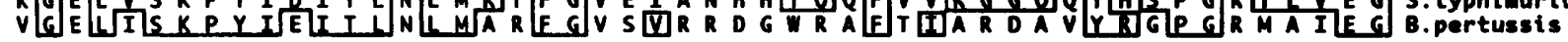

DASSASYFLAAAAIXGG TVRVTGIGKKSVOGDTKFADVLERMGARVTRGDY. pestis

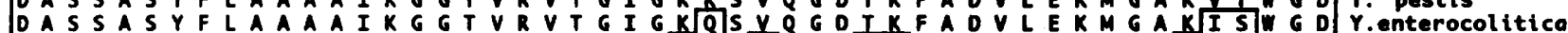

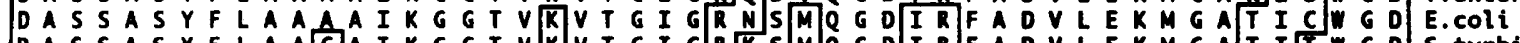
D A S S S A S Y F L A A

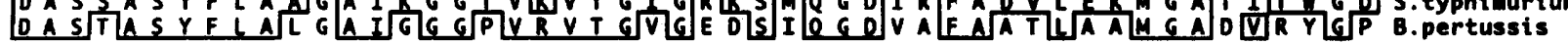

DYIECSRG- - - - - ELOGIDMOMNHIPOAAMTIATTALFATGPTIIRNI Y. pestis

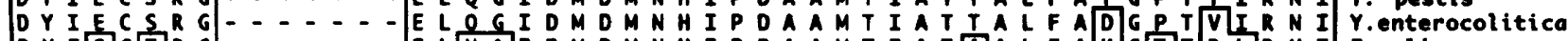

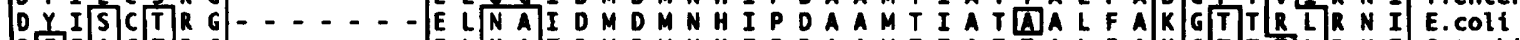

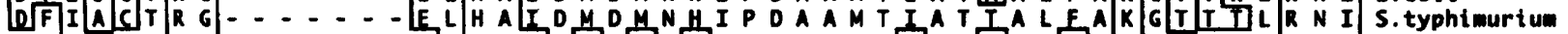

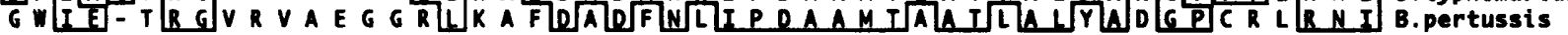

PNWRVKETDRLTAMATELRKVGAEVEEGEOYIRVVPPIQ - - LAADIGTYY. pestis

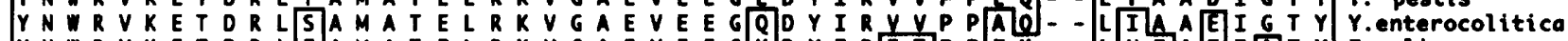

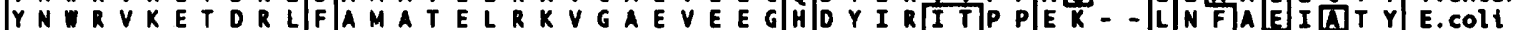

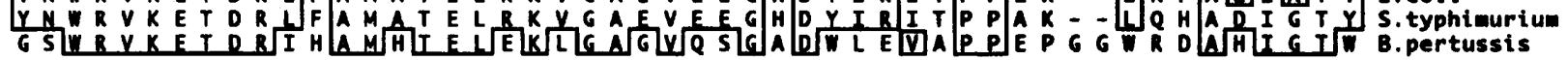

DOHRMAMCFSLVALSDTPVTILOPKCTARTFPOYFEQFAR]- - - - $\mathbb{R}$.

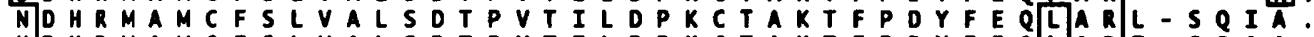

NDHRMAMCFSLVALSDTPVTILDPKCTAKTFPDYFEQLLARI-SQAA.

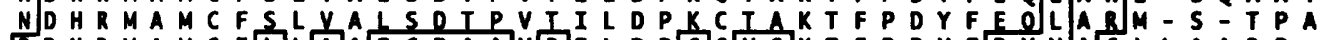

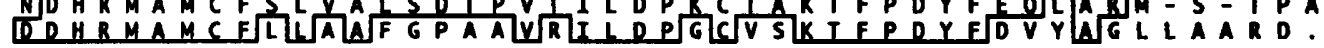

Y. pestis

Y.enterocolitico

E.coli

S. typhimurium

B.pertussis

Fig. 2. Alignment of the deduced amino acid sequences encoded by aroA genes from $Y$. pestis, $Y$. enterocolitica, $E$. coli, S. typhimurium and $B$. pertussis. Amino acids identical to those of $Y$. pestis protein are boxed.

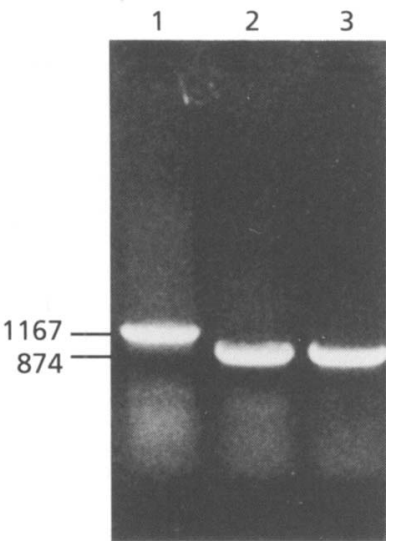

Fig. 3. Amplification of the aroA gene of $Y$. pestis GB (lane 1), $Y$. pestis GB $\triangle a r O A$ (lane 2) and PGPYP $\triangle A 7$ (lane 3 ). The lengths of the bands on the gel are indicated in bp. sequence from the $Y$. pestis aro $A$ gene and those from other species (Fig. 2). The aro $A$ gene in other species of the Enterobacteriaceae has been shown to form part of an operon with $\operatorname{ser} C$, which is located upstream of aro $A$ (O'Gaora et al., 1989; Duncan \& Coggins, 1986). The nucleotide sequence upstream from the aro $A$ gene was homologous to $\operatorname{ser} C$ of $Y$. enterocolitica (data not shown). Inspection of the sequence of the intergenic region did not reveal any obvious promoters, suggesting that the aro $A$ gene of $Y$. pestis is transcribed as part of an operon. A deletion was produced in the cloned fragment of the $\operatorname{aro} A$ gene and this was used to generate the aro-defective mutant strain of $Y$. pestis, GB $\Delta$ aro $A$. A single copy of the aro $A$ gene containing the lesion was confirmed by PCR. This avoided the need for Southern blots as the DNA of $Y$. pestis GB is resistant to digestion due to DNAmethylation systems, including the dam and $\mathrm{dcm}$ systems found in other enterobacteria (Demidova et al., 1984). 
Previous work has evaluated the relative susceptibility of various animal models to identify a suitable model for the evaluation of candidate plague vaccines (Meyer et al., 1974c). Although various nonhuman primates were considered to reflect most closely the disease in humans, mice and guinea-pigs were also identified as being susceptible to $Y$. pestis infection and able to produce an immune response upon vaccination. GB $\triangle a r o A$ was attenuated in guinea-pigs in vivo. Only $1 / 15$ animals appeared sick, there were no deaths and healthy animals appeared to have cleared the bacteria as there were no abscesses on their major internal organs. The induced immunity after a single low dose of the mutant protected against homologous challenge with a dose of $9 \cdot 26 \times 10^{6}$ c.f.u. of the virulent wild-type strain and significant titres of specific anti-F1 and anti- $V$ antibodies were detected in sera from immunized animals. High antibody titres to $\mathrm{F} 1$ antigen and $\mathrm{V}$ antigen have been shown to correlate with protection against plague (Meyer et al., 1974b; Leary et al., 1995; Motin et al., 1994). Surprisingly, the aro-defective mutant was still virulent in mice, although the increased time to death of the mice would suggest that the rate of growth in vivo was reduced. The virulence of $\mathrm{GB} \Delta$ aro $A$ in mice contrasts with the behaviour of a $\triangle$ aro $A$ mutant of $Y$. enterocolitica, which was not lethal in the mouse model (Bowe et al., 1989). Y. pestis is known to possess additional genetic elements encoding a variety of virulence determinants, e.g. unlike $Y$. enterocolitica, $Y$. pestis produces a toxin which is active in mice. This may go some way towards explaining the observed host-dependent nature of the attenuation. The inability of the $Y$. enterocolitica $\triangle a r o A$ mutant to cause disease was linked with the rapid clearance of the bacteria from the reticulo-endothelial system. It has been suggested that this may indicate an increased susceptibility of Yersinia to bacterial clearance mechanisms and that Yersinia may rely on rapid and overwhelming growth to kill mice (Bowe et al., 1989). Our results provide a contrasting result; the $\mathrm{LD}_{50}$ of $\mathrm{GB} \triangle$ aro $A$ was similar to that of the wild-type strain. The ability of the $\triangle a r o A$ mutant of $Y$. pestis to grow in vivo also contrasts with results obtained with $\triangle a r o A$ mutants of other bacterial species, but is supported by the observation that phenylalanine-dependent mutants of $Y$. pestis are not attenuated in mice (Burrows, 1960,1963). A previous examination of host specificity of Brazilian isolates of $Y$. pestis found that low levels of free asparagine were responsible for a mouse-virulent strain being nonvirulent in guinea-pigs (Burrows \& Gillet, 1971). A similar difference in aromatic amino acid levels may provide an explanation for the attenuation of the $Y$. pestis $\triangle$ aro $A$ mutant in guinea-pigs.

The persistence, but inability to grow, in reticuloendothelial tissues observed with $S$. typhimurium $\Delta a r o A$ has been attributed to the inability of the bacteria to synthesize PABA and DHB, which are essential for growth. Our results show that growth of $S$. typhimurium $\triangle$ aro $A$ ceased after subculturing through media lacking PABA and DHB, whereas the growth of the $Y$. pestis mutant was not limited in the same media. It is therefore possible that $Y$. pestis possesses an alternative biosynthetic pathway which bypassed the mutation or alternative scavenging mechanisms for metabolites. In addition to preventing folate production, mutation in the aro $A$ gene blocks the synthesis of the iron-chelating siderophore enterochelin in $S$. typhimurium. It is possible that after growth in defined media, starvation of PABA and DHB inhibited enterochelin synthesis in S. typhimurium SL3261 and therefore iron limitation impaired bacterial multiplication. $Y$. pestis possesses a complex system for scavenging iron, including iron chelation by the siderophore yersiniabactin and a haemin-uptake pathway (Straley \& Perry, 1995). It would be expected that yersiniabactin synthesis is prevented in GB $\Delta$ aro $A$, as has been shown for the $\triangle a r o A$ strain of $Y$. enterocolitica (Heesemann et al., 1993). Although the mutation in the aro $A$ gene may have prevented siderophore production in $Y$. pestis, the availability of alternative iron-uptake mechanisms may have been the factor that permitted growth of GB $\triangle$ aro $A$ in the defined media by bypassing the blockage in the siderophore iron-transport system.

It has been known for some time that different virulence factors are important in different species; e.g. a classically attenuated mutant, $Y$. pestis EV76, which was classified as 'harmless' in guinea-pigs was subsequently shown to be virulent in nonhuman primates (Meyer et al., 1974c). Our finding that a $\triangle$ aro $A$ mutant is able to cause disease in one host animal species while being attenuated in another raises the possibility that $\Delta$ aro mutants of other bacteria may be virulent in alternative animal models.

\section{REFERENCES}

Alexander, J. E., Andrew, P. W., Jones, D. \& Roberts, I. S. (1993). Characterization of an aromatic amino acid-dependent Listeria monocytogenes mutant: attenuation, persistence and ability to produce protective immunity in mice. Infect Immun 61, 2245-2248.

Bowe, F., O'Gaora, P., Maskell, D., Cafferkey, M. \& Dougan, G. (1989). Virulence, persistence and immunogenicity of Yersinia enterocolitica $\mathrm{O}: 8$ aro $A$ mutants. Infect Immun 57, 3234-3236.

Burrows, T. W. (1960). Biochemical properties of virulent and avirulent strains of bacteria: Salmonella typhosa and Pasteurella pestis. Ann NY Acad Sci 88, 1125-1135.

Burrows, T. W. (1963). Virulence of Pasteurella pestis and immunity to plague. In Ergebnisse der Mikrobiologie Immunitatsforschung und Experimentellen Therapie, pp. 59-113. Berlin: Springer-Verlag.

Burrows, T. W. \& Gillet, W. A. (1971). Host specificity of Brazilian strains of Pasteurella pestis. Nature 229, 51-52.

Clements, J. D., Bao, J. X. \& Cardenas, L. (1992). Use of attenuated bacteria as live oral vaccine vectors. In Recombinant $D N A$ Vaccines: Rationale and Strategy, pp. 293-322. Edited by R. E. Isaacson. New York: Marcel Dekker.

Cowling, P. \& Moss, P. (1994). Infectivity of pneumonic plague. $\mathrm{Br}$ Med J 309, 1369.

Davis, K. J., Fritz, D. L., Pitt, M. L., Welkos, S. L., Worsham, P. L. \& Friedlander, A. M. (1996). Pathology of experimental pneumonic plague produced by fraction 1-positive and fraction 1-negative Yersinia pestis in African green monkeys (Cercopitheus aethiops). Arch Pathol Lab Med 120, 156-163.

Demidova, G. V., Goncharov, E. K. \& Tynyanova, V. I. (1984). Comparison of the recognition site specificities of adenyl and 
cytosyl DNA methylases of Yersinia pestis EV76 dam and dcm with E. coli methylases. Biokbimiya 49, 1594-1597.

Dower, W. J., Miller, J. F. \& Ragsdale, C. W. (1988). High efficiency transformation of $E$. coli by high voltage electroporation. Nucleic Acids Res 16, 6127-6145.

Drozdov, I., Anisimov, A. P., Samoilova, L. V., Yezhov, I. N., Yeremin, S. A., Karlyshev, A. V., Krasilnikova, V. M. \& Kravchenko, V. I. (1995). Virulent non-capsulate Yersinia pestis variants constructed by insertion mutagenesis. $J$ Med Microbiol 42, 264-268.

Duncan, K. \& Coggins, J. R. (1986). The $\operatorname{ser} C$-aro $A$ operon of Eschericbia coli. Biocbem J 234, 49-57.

Dybvig, K., Hollinshead, S. K., Heath, D. G., Clewell, D. B., Sun, F. \& Woodard, A. (1992). Degenerate oligonucleotide primers for enzymatic amplification of $\operatorname{rec} A$ sequences from Gram positive bacteria and mycobacteria. $J$ Bacteriol 174, 2729-2732.

Grinter, N. J. (1983). A broad-host-range cloning vector transposable to various replicons. Gene 21, 133-143.

Havard, H. L., Hunter, S. E. C. \& Titball, R. W. (1992). Comparison of the nucleotide sequence and development of a PCR test for the epsilon toxin gene of Clostridium perfringens. FEMS Lett 97, 77-82.

Heesemann, J., Hantke, K., Vocke, T., Saken, E., Rakin, A., Stojiljkovic, I. \& Berner, R. (1993). Virulence of Yersinia enterocolitica is closely associated with siderophore production, expression of an iron-repressible outer membrane polypeptide of $65,000 \mathrm{Da}$ and pesticin sensitivity. Mol Microbiol 8, 397-408.

Hoiseth, S. K. \& Stocker, B. A. D. (1981). Aromatic-dependent Salmonella typhimurium are non-virulent and effective as live vaccines. Nature 291, 238-239.

Homchampa, P., Strugnell, R. A. \& Adler, B. (1992). Molecular analysis of the aro $A$ gene of Pasteurella multocida and vaccine potential of a constructed aro A mutant. Mol Microbiol 6, 3585-3593.

Ivins, B. E., Welkos, S. L., Knudson, G. B. \& Little, S. F. (1990). Immunization against anthrax with aromatic compound-dependent (Aro ${ }^{-}$) mutants of Bacillus antbracis and with recombinant strains of Bacillus subtilis that produce anthrax protective antigen. Infect Immun 58, 303-308.

Leary, S. E. C., Williamson, E. D., Griffin, K. F., Russell, P., Eley, S. M. \& Titball, R.W. (1995). Active immunization with recombinant $\mathrm{V}$ antigen from Yersinia pestis protects against plague. Infect Immun 63, 2854-2858.

Levine, M. M., Herrington, D., Murphy, J. R., Morris, J. G., Losonsky, G., Tall, B., Lindberg, A. A., Svenson, S., Baqar, S., Edwards, M. F. \& Stocker, B. (1987). Safety, infectivity, immunogenicity and in vivo stability of two attenuated auxotrophic mutant strains of Salmonella typhi, 541Ty and 543Ty, as live oral vaccines in humans. J Clin Invest 79, 888-902.

MacFarland, W. C. \& Stocker, B. A. D. (1987). Effect of different purine auxotrophic mutations on mouse-virulence of a Vi-positive strain of Salmonella dublin and two strains of Salmonella typhimurium. Microb Pathog 3, 129-141.

Marmur, J. (1961). A procedure for the isolation of deoxyribonucleic acid from micro-organisms. $J$ Mol Biol 3, 208-218.

Marshall, J. D., Bartelloni, P. J., Cavanaugh, D. C., Kadull, P. J. \& Meyer, K. F. (1974). Plague immunization. II. Relation of adverse clinical reactions to multiple immunizations with killed vaccine. $J$ Infect Dis 129, S19-S25.

Maskell, D., Sweeny, K., O'Callaghan, D., Hormaeche, C., Liew, F. \& Dougan, G. (1987). Salmonella typhimurium aro $A$ mutants as carriers of the Escherichia coli heat-labile enterotoxin B subunit to the secretory and systemic immune systems. Microb Pathog 2, 211-221.

McGhee, J. R., Mestecky, J., Dertzbaugh, M. T., Eldridge, J. H., Hirasava, M. \& Kiyono, H. (1992). The mucosal immune system: from fundamental concepts to vaccine development. Vaccine $\mathbf{1 0}$, 75-88.

Meyer, K. F. (1970). Effectiveness of live or killed plague vaccines in man. Bull WHO 42, 653-666.

Meyer, K. F., Cavanaugh, D. C., Bartelloni, P. J. \& Marshall, J. D. (1974a). Plague immunization. I. Past and present trends. J Infect Dis S129, S13-S18.

Meyer, K. F., Hightower, J. A. \& McCrumb, F. R. (1974b). Plague immunization. VI. Vaccination with the fraction 1 antigen of Yersinia pestis. J Infect Dis S129, S41-S45.

Meyer, K. F., Smith, G., Foster, L. E., Brookman, M. \& Sung, M. (1974c). Live, attenuated Yersinia pestis vaccine: virulent in nonhuman primates, harmless to guinea pigs. J Infect Dis $\mathbf{S 1 2 9}$, S85-S120.

Miller, V. \& Mekalanos, J. (1988). A novel suicide vector and its use in construction of insertion mutations: osmoregulation of outer membrane proteins and virulence determinants in Vibrio cholerae requires toxR. $J$ Bacteriol 170, 2575-2583.

Motin, V. L., Nakajima, R., Smirnov, G. B. \& Brubaker, R. R. (1994). Passive immunity to yersiniae mediated by anti-recombinant $\mathrm{V}$ antigen and protein A-V antigen fusion peptide. Infect Immun 62, 4192-4201.

O'Gaora, P., Maskell, D., Coleman, D., Cafferkey, M. \& Dougan, G. (1989). Cloning and characterization of the $\operatorname{ser} C$ and aro $A$ genes of Yersinia enterocolitica and construction of an aro $A$ mutant. Gene 84, 23-30.

Oyston, P. C. F., Williamson, E. D., Leary, S. E. C., Eley, S. M., Griffin, K. F. \& Titball, R.W. (1995). Immunization with live recombinant Salmonella typhimurium aro $A$ producing $\mathrm{F} 1$ antigen protects against plague. Infect Immun 63, 563-568.

Reed, L. J. \& Muench, H. (1938). A simple method for estimating fifty percent endpoints. Am J Hyg 27, 493-497.

Reisman, R. E. (1907). Allergic reactions due to plague vaccine. $J$ Allergy 46, 49-55.

Roberts, M., Maskell, D., Novotony, P. \& Dougan, G. (1990). Construction and characterization in vivo of Bordetella pertussis aro $A$ mutants. Infect Immun 58, 732-739.

Russell, P., Eley, S. M., Hibbs, S. E., Manchee, R. J., Stagg, A. J. \& Titball, R. W. (1995). A comparison of plague vaccine U.S.P. and EV76 vaccine induced protection against Yersinia pestis in a murine model. Vaccine 13, 1551-1556.

Sambrook, J., Fritsch, E. F. \& Maniatis, T. (1989). Molecular Cloning: a Laboratory Manual, 2nd edn. Cold Spring Harbor, NY: Cold Spring Harbor Laboratory.

Sigwart, D. F., Stocker, B. A. D. \& Clements, J. D. (1989). Effect of a pur $A$ mutation on efficacy of Salmonella live-vaccine vectors. Infect Immun 57, 1858-1861.

Straley, S. C. \& Bowmer, W. S. (1986). Virulence genes regulated at the transcriptional level by $\mathrm{Ca}^{2+}$ in Yersinia pestis include structural genes for outer membrane proteins. Infect Immun 51, 445-454.

Straley, S. C. \& Perry, R. D. (1995). Environmental modulation of gene expression and pathogenesis in Yersinia. Trends Microbiol 3, 310-317.

Vaughan, L. M., Smith, P. R. \& Foster, T. J. (1993). An aromaticdependent mutant of the fish pathogen Aeromonas salmonicida is attenuated in fish and is effective as a live vaccine against the salmonid disease furunculosis. Infect Immun 61, 2172-2181.

Received 16 November 1995; revised 12 February 1996; accepted 14 February 1996. 